EDITORIAL

\title{
Los 35 años de la Revista Peruana de Biología
}

\section{Leonardo Romero}

Editor Jefe, Instituto de Investigación de Ciencias Biológicas Antonio Raimondi, Facultad de Ciencias Biológicas, Universidad Nacional Mayor de San Marcos. Apartado 11-0058, Lima 11, Perú. Email: Iromeroc@unmsm.edu.pe

\section{El inicio}

"Su continuidad y perfección [de la Revista Peruana de Biología] estarán aseguradas, solamente, con la participación efectiva de todos nosotros" (Cesar Acleto, Asociación de Biólogos de la Universidad de San Marcos, Comité editor de la Rev peru biol). Estas fueron las últimas líneas de la presentación del primer número de la Revista Peruana de Biología y que vieron la luz en 1974. La Revista nació por iniciativa de los miembros de la Asociación de Biólogos de la Universidad de San Marcos (ABUSM), en esa época era el grupo más organizado de biólogos en todo el Perú, las personas que decidieron este nacimiento lo hicieron con convicción académica y mística. Sin embargo la principal flaqueza se podría vislumbrar en el número de artículos ( 5 trabajos originales y dos notas científicas en el primer número). Entonces aquella última frase de la Presentación tendría que entenderse como una solicitud imperante y coactiva. Entre el año 1974 y 1997 habían transcurrido 23 años y publicado 31 artículos, la mayoría del área de lo que ahora denominamos biodiversidad, eran minuciosos, descriptivos y sentaban las bases para posteriores investigaciones. En el ańo 1998 reapareció la Revista, había sido cedida por la ABUSM a la Facultad de Ciencias Biológicas de la Universidad Nacional Mayor de San Marcos (UNMSM),

\section{Dos escenarios, la diferencia con los pioneros}

Los editores en el primer volumen fueron Manuel Tantaleán, Julio Paz, Carlos Paredes, Cesar Acleto y Juana Coha, en los siguientes volúmenes, del dos al cuatro, los editores fueron Cesar Acleto y Carlos Paredes. A lo largo de esos 23 años, en los interiores de casi todas, se puede leer "Este numero fue financiado por los autores" y en uno "este número fue financiado por el CONCYTEC”. El esfuerzo por dar a conocer las investigaciones que realizaban era parte de lo que se comunicaba en esas revistas. Posteriormente, desde el año 1998 la UNMSM empieza la im- plementación de una política que incluía diferentes herramientas con el fin de desarrollar la investigación. Una de esas herramientas era auspiciar la publicación de una revista científica por cada facultad. Entonces el Instituto de Ciencias Biológicas Antonio Raimondi decidió adoptar a la Revista Peruana de Biología y es así que la Revista comienza su segundo periodo.

Dentro de la universidad las condiciones habían cambiado, se había pasado de un sistema departamentalista al de facultades, la investigación comenzó a ser reconocida uno de los fines de la universidad y los investigadores comenzaron a ser evaluados según su producción científica. Tácitamente se esperaba que las revistas de investigación serian colmadas por articulos productos de las investigaciones realizadas. Se creo un lugar oficial para una revista científico y los editores y su labor comenzaron a ser reconocidos, las actividades de la revista comenzaron a estar presentes en los planes de trabajo y en las actividades. Económicamente cada año el Consejo Superior de Investigación aporta un apoyo parcial para la impresión de la revista y la Facultad se compromete con su funcionamiento de la revista.

En el nivel nacional, empezó el desarrollo de una política de investigación y se consolidaron planes para la difusión de las investigaciones, y se realizaron periódicamente actividades de promoción y capacitación para editores con la finalidad de mejorar la calidad de las revistas científicas en el Perú.

En el nivel internacional las revistas científicas comienzan a consolidarse como las proveedoras de indicadores de producción científica, la INTERNET es la tecnológica que permite el acceso a la información, los conceptos de sociedad de la información y del conocimiento cobran vida y se hacen reales. Los avances de la tecnología obligan a cuestionar el status quo sobre la distribución del conocimiento. Cada vez nos damos cuenta de la existencia de una brecha tecnológica y de conocimientos y del tremendo esfuerzo que deben realizar países como el nuestro para

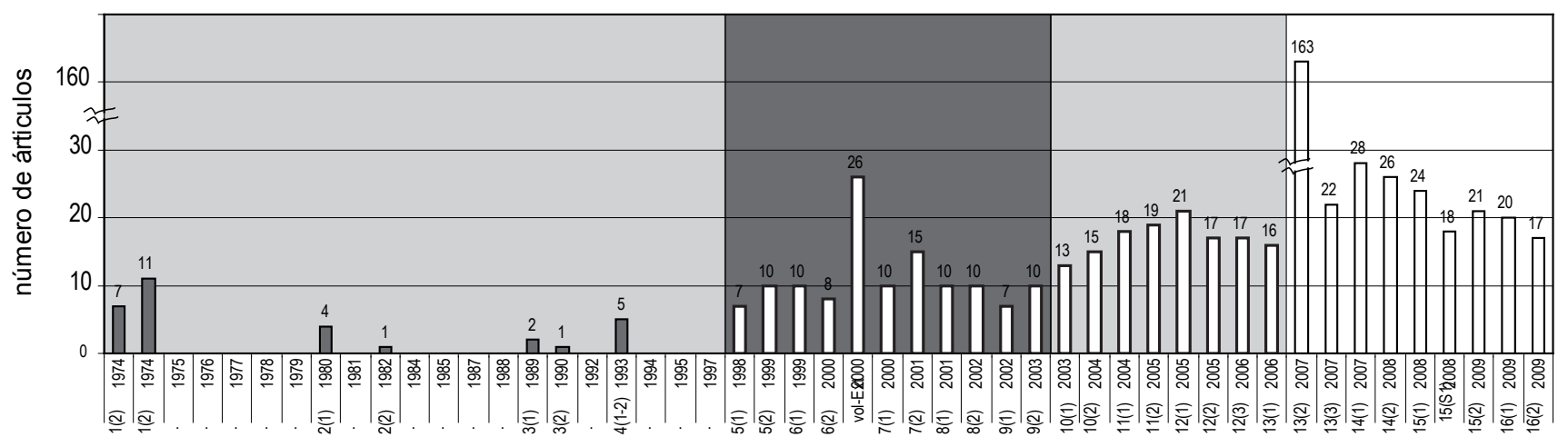

volumen(número)-año

La figura muestra la cantidad de articulos por cada numero de Rev peru biol, números sobre las barras. Se consideran los años en que fueron publicados y los volúmenes y numeros respectivos. La primera etapa de la Revista a cargo de la Asociación de Biólogos de la Universidad de San Marcos, en la segunda etapa podemos distinguir un primer momento con un número de artículos alrededor de 10. Un segundo momento con una producción alrededor de 15 artículos y recientemente alrededor de 20 articulos. 
cubrirla. Surgen los problemas con la erosión de la información, el desconocimiento es más patente en las nuevas generaciones, a pesar que ellas disponen de nuevos medios y tecnologías más potentes, pero a su vez más restrictivas con respecto al acceso de la información. Cobra fuerza la filosofía del Open Access como una actitud ante la brecha del conocimiento y el acceso a él, una brecha la mas de veces injusta y que podría perjudicar a toda la sociedad humana.

Hacia una revista de excelencia o emprendiendo una guerra por nuestro conocimiento

¿Un conocimiento que es descubierto o generado por una institución del estado, porqué debe quedar aislado de la sociedad? Es una pregunta que planteada, en la ultima década, en muchos lugares y con diferentes matices. Para algunos países se refiere a los altísimos costos (alrededor de millones de dólares) que tienen que pagar las bibliotecas para mantenerse actualizadas, $\mathrm{y}$ que paradójicamente lo hacen para satisfacer a los investigadores que han producido el conocimiento, es decir compran lo que produjeron. En otros países es simplemente desconocer la especie descubierta, el sistema resuelto, el compuesto que salva las vidas, detalles de nuestro pasado, y otras tantas cosas que suceden en nuestro territorio, nuestros recursos y nuestra sociedad. Muchas veces que son producidos por nuestros investigadores y al que tal vez nunca tendremos acceso.

La Rev peru biolnecesita consolidarse dentro de las batallas por documentar el conocimiento biológico generado en el Perú, ponerlo a disposición de la sociedad, la actual y todas las siguientes generaciones; que las paginas de la Revista sean las bases de las siguientes investigaciones y estas a su vez de otras publicaciones. Es por eso vital para la Revista contar con medios tecnológicos modernos, que satisfagan las necesidades de los investigadores y de la sociedad. Esta batalla la ganaremos cambiando a estándares de publicaciones de mayor uso, a formatos con mayores posibilidades de difusión e intercambio, participando en la socialización de la información.
La batalla por la documentación y preservación de la información es difícil; pero a la larga mas fácil de resolver que la batalla contra la perversidad de los investigadores. Esta batalla fue librada en la primera época de la Revista y la actitud de alejamiento e indiferencia de los investigadores provoco el colapso y la Revista perdió. Los pioneros de la Revista no contaron con un medio ambiente como el actual, la mística cedió ante otros intereses. Aunque, en la actualidad el escenario permite cierto optimismo, observamos una amenaza similar a la de la primera época de la Revista, por un lado los investigadores no se cohesionan como una comunidad científica, suficientemente activa y trascendente como para impulsar la Revista a los niveles internacionales esperados.

\section{Solamente, con la participación efectiva de todos nosotros}

La formación de una comunidad científica debe convertirse en parte sustancial de la política de investigación del Instituto de Ciencias Biológicas y de toda la universidad. Si bien los incentivos como una política de investigación pueden redundar sobre la cantidad de investigación, la calidad e innovación de las investigaciones dependerán de la consolidación de un grupo de individuos interactuantes, criticos, creadores e identificados con una comunidad científica. Las comunidades científicas con redes complejas de individuos que se extienden mas allá de países y han demostrado que al intercambiar conocimientos e información desarrollan la ciencia y tecnología. Aprovechar los trabajos con investigadores extranjeros y nacionales para incrementar y fortalecer una red social que permita expandir nuestra comunidad científica pueden ser metas que permitirán impulsar la Revista.

La Revista es un medio para comunicación, preservación, difusión y también para integración, si en los próximos años logramos consolidar y extender la comunidad científica, podremos sobrevivir y lograr la excelencia de las revistas del main stream, pero sobretodo estaremos contribuyendo a preservar el acceso de los conocimientos para las generaciones que vendrán. 